\title{
Brazilian Nursing Challenges for Equity and Sustainability
}

Emiko Yoshikawa Egry'

ORCID: 0000-0003-0974-0315

'Nurse. Emeritus Professor at Escola Paulista de Enfermagem, Universidade Federal de São Paulo. Visiting Professor at Escola Paulista de Enfermagem, Universidade Federal de São Paulo (20192020). CNPq Senior Productivity Researcher (2019-2024). Based on the Conferência Magna de Encerramento do 71 CBEn (Magna Closing Conference of 71 CBEn), Manaus, Amazonas, November 2019, spoken by Emiko Yoshikawa Egry. São Paulo, São Paulo, Brazil.

How to cite this article: Egry EY. Desafios da Enfermagem brasileira para a equidade e a sustentabilidade. Rev Bras Enferm. 2020;73(3):e2020n3. doi: http://dx.doi.org/10.1590/0034-7167-2020730301

Corresponding author:

Emiko Yoshikawa Egry

E-mail:emiyegry@usp.br
The $71^{\text {st }}$ Brazilian Congress of Nursing, based in the city of Manaus, state of Amazonas, addressed topics related to the central purpose - Nursing and the meanings of equity - since the Conferência Magna de Abertura (Magna Opening Conference). The illustrious Professor Jaime Breilh spoke at the Congress, a world reference in the field of critical epidemiology, including several round tables, symposia, seminars, lectures and free topics.

All over the world, there is a growing interest in adopting practices capable of innovating and reforming health systems to meet the health needs of social groups in the territories, which have been changing due to demographic, epidemiological and ecological-environmental changes. Efforts by different countries to improve health systems have very expressive results for those who have adopted Primary Health Care (PHC) as a concept and practice for the inclusion of almost the entire population.

We understand that the less disparities between social groups, societies, the greater the response to health actions. However, the greater the gap in the population's daily living conditions, the greater the challenges for formulators and executors of public health policies. This is because the response to health interventions depends primarily on understanding or, to use the word currently in vogue, adherence to care or therapeutic proposals ${ }^{(1)}$.

Therefore, in our understanding, health is totally dependent on the quality of life, which, in turn, is dependent on the production and social reproduction of the social groups in our territory ${ }^{(1)}$.

The 2030 Agenda, to which our country subscribes, contains an immense challenge, even if, when looking at the Sustainable Development Goals, we focus only on those directly related to health. We can say that some social groups will be able to easily reach many of the SDGs, while others do not stand a chance. This is because the deterioration in living conditions and, therefore, in the health of our population, is such that we have a contingent the size of Belgium of miserable people, that is, below the poverty line, living on less than 145 reais a month ${ }^{(2)}$.

A major challenge for meeting needs and addressing vulnerabilities is related to the health workforce. The scarcity of professionals and their poor geographical distribution are a major problem, compounded by insufficient training to provide quality health care. Furthermore, all of this must in some way help to ensure sustainability, that is, to look deeply at Agenda 2030

However, sustainability itself, as it is mostly understood, is supportive of inequity, inequality, the current situation of accumulation of wealth produced by very few, and, for this very reason, it is also supportive of neoliberal capitalism ${ }^{(3-4)}$.

We still need to consolidate and advance, in the first place, in the recognition of poverty as a structural issue of societies, which, daily, "manufactures" and maintains poverty by not understanding the processes of social production that result in inequities in both insertion and sharing. socially produced goods. The ultra-exploitation of capital that occurs legally (but not morally) in neoliberalism that prevails in the country does not problematize and, therefore, cannot overcome inequalities. 
If the health sector, including nursing, looks at the roots of the production of inequalities as something structural and not as something contingent, it could, from the start, build and enforce the instruments for overcoming them. It is necessary to train professionals who understand the origin of hunger, poverty and poor quality of life that will result in poor quality in terms of health. It is not enough to improve the clinic; it is necessary to invest in the training of nursing professionals to improve intervention in vulnerable social groups.

Corburn states that:

More people live in cities than at any other time in human history and health inequalities are increasing. Health inequities are avoidable differences in the social, environmental and political conditions that shape morbidity and mortality and disproportionately burden the poor, racial, ethnic and religious minorities and migrants. By linking urban locations and health inequities, research and action highlight the challenges of achieving urban environmental justice ${ }^{(5)}$.

Furthermore, it is never too much to remember something that is so dear to us, because we are a profession formed by women who, in this country and in many others too, suffer from gender subordination on a daily basis. However, we also preserve subalternizing stereotypes and, therefore, perpetuators of this condition, by naturalizing subalternity, both in terms of gender, as well as race/ethnicity and generation, among others.

It will not be easy in these times, but it is absolutely necessary to understand where subalternity comes from, what mechanisms are involved in its maintenance and also which struggles were successful in overcoming some of the gender conditions.

Nurses, undergraduate students, graduate students, nursing technicians, managers, we all have to learn that this is a fact of reality that cannot be tackled just by studying ways to elucidate domestic violence, if we do not understand that we are human beings with the same rights ${ }^{(6)}$.

We believe that there is a paradigm shift: human beings and the planet. In the initial training and successive professional qualification, we have to problematize the impact caused by our care actions, from the inputs used, and guide the use of renewable energy and biodegradable products. For example, mentioning only the forms of disposal, there are already studies on the waste produced in health facilities.

Our education must have this ecological awareness: why in today's times do institutions ask for printed theses and dissertations? Has anyone analyzed the impact of this? How much do we "charge" for global warming when hosting events that mobilize thousands of people using air transport, the most aggressive of all? What source of energy does our electricity come from, so important for the maintenance of equipment in hospitals, basic units or schools? Are we going to build new teaching and health care equipment without thinking of better solutions for this?

I invite the readers of this journal to reflect on ways to change the course of things for us, for the population and for the world:

- Are we going to revisit our training curricula in order to cover the concepts of equity and sustainability across the board?

- Are we going to revisit our care protocols and regulations to house the sharing of care decisions and also the environment?

- Are we going to look more densely at the social groups we assist or care for instead of generalizing problems, health needs and vulnerabilities by average?

- Are we going to give a voice and develop critical awareness of the different subjects of our care processes, which includes patients, clients, users and their families, social groups and communities?

- And when we revisit, will we create action plans based on the objective reality of both our object of care and of students in training and workers, so that we are able to draw new, more critical and reflective horizons of overcoming?

Are we going to put into action proposals for a radical change in our nursing and health practices and policies towards equity and sustainability?

\section{REFERENCES}

1. Egry EY, Fonseca RMGS, Oliveira MAC, Bertolozzi MR. Nursing in Collective Health: reinterpretation of objective reality by the praxis action. Rev Bras Enferm. 2018;71:710-5. doi: 10.1590/0034-7167-2017-0677

2. Organização das Nações Unidas. Assembleia Geral das Nações Unidas. Transforming our world: the 2030 agenda for sustainable development. Draft for consultation [Internet]. ONU. 2015[cited 2020 Jan 30]. Available from: http://www.who.int/hrh/resources/glob-strat-hrh_workforce2030.pdf?ua=1

3. Nascimento AB, Egry EY. Os planos municipais de saúde e as potencialidades de reconhecimento das necessidades em saúde: estudo de quatro municípios brasileiros. Saúde Soc. 2017;26(4):1-11. doi: 10.1590/s0104-12902017170046

4. Peduzzi M, Aguiar C, Lima AMV, Montanari PM, Leonello VM, Oliveira MR. Expansion of the interprofessional clinical practice of Primary Care nurses. Rev Bras Enferm. 2019;72(Sup1):114-21. doi: 10.1590/0034-7167-2017-0759

5. Corburn J. Urban place and health equity: critical issues and practices. Int J Environ Res Public Health 2017, 14, 117; doi:10.3390/ijerph14020117

6. Bryant-Lukosius D, Martin-Misener R. ICN Policy Brief. Advanced Practice Nursing: an essential component of country level human resources for health. ICN [Internet]. 2016[cited 2020 Jan 30]. Available from: http://www.icn.ch/images/stories/documents/pillars/sew/HRH/ICN_Policy_Brief_6.pdf 